\title{
Automatic Control of the Carbon Potential of Furnace Atmospheres without Adding Enriched Gas
}

\author{
YONG-CHWANG CHEN
}

An approach has been proposed in this article for controlling the carbon potential of furnace atmosphere without the need to add enriched gas for the sake of simplifying the process of carbon potential control and consequently lowering the cost of atmosphere. The atmosphere was generated by reacting an $\mathrm{N}_{2}+\mathrm{H}_{2} \mathrm{O}$ mixture with hot charcoal. An oxygen sensor and a computer were used for controlling the carbon potential of the atmosphere through controlling the temperature of charcoal instead of adding an enriched gas to the atmosphere. The control result was evaluated from (a) the stability of oxygen partial pressure of the furnace atmosphere and (b) the equilibrium carbon content of the steel heated in the furnace atmosphere. The result of controlling carbon potential with this method was indicated by observed experiments to be satisfactory; i.e., the deviation of carbon potential was below 0.06 pct. There was especially no need to add enriched gases to the atmosphere.

\section{INTRODUCTION}

THE carbon potential control of furnace atmosphere is rather important in the heat treatment of steel, because the carbon potential of atmosphere has intimate relationships with carbon distribution, surface hardness, and hardened depth of the steel treated under the atmosphere. Three methods are currently used in industry for controlling the carbon potential of furnace atmospheres: ${ }^{[1-4]}$ (1) controlling carbon potential by controlling the atmosphere's $\mathrm{O}_{2}$ partial pressure, which is monitored by using an oxygen sensor; (2) controlling carbon potential through controlling the atmosphere's $\mathrm{CO}_{2}$ content, which is measured by using an infrared analyzer; and (3) controlling carbon potential by controlling the atmosphere's $\mathrm{H}_{2} \mathrm{O}$ content, which is detected by using a dew cell. The controlling principle for any of these three methods is the addition of an enriched gas $\left(\mathrm{CH}_{4}\right.$ or $\left.\mathrm{C}_{3} \mathrm{H}_{8}\right)$ to the atmosphere for the sake of regulating the level of $\mathrm{O}_{2}$ partial pressure, $\mathrm{CO}_{2}$ content, or $\mathrm{H}_{2} \mathrm{O}$ content of the atmosphere. The carbon potential of the atmosphere is basically controlled by controlling the amount of enriched gas being added. This principle is applied to control the carbon potential of atmospheres generally being used in industry, such as endothermic gas, exothermic gas, methonal dissociated gas, nitrogen-based atmosphere, etc.

Water-gas atmosphere is one of the furnace atmospheres developed by National Taiwan University in recent years. ${ }^{15-10]}$ The components of water-gas atmosphere are similar to those of an endothermic gas, namely, $\mathrm{N}_{2}, \mathrm{CO}, \mathrm{H}_{2}, \mathrm{CO}_{2}, \mathrm{H}_{2} \mathrm{O}, \mathrm{CH}_{4}$, and minute amounts of $\mathrm{O}_{2}$. The carbon potential of water-gas atmosphere can indeed be controlled by adding proper amounts of enriched gas. However, adding enriched gas to water-gas atmosphere will raise the cost of the atmosphere. Solving this problem with a different method has therefore been the attempt of this study. The carbon

YONG-CHWANG CHEN, Associate Professor, is with the Department of Mechanical Engineering, National Taiwan University, Taipei, Taiwan.

Manuscript submitted November 10, 1992. potential of water-gas atmosphere has been controlled by controlling the generation condition of the atmosphere instead of adding enriched gas to the atmosphere. Can the carbon potential be effectively controlled by using this method? No investigation on this point has ever been reported.

Water-gas atmosphere is generated by reacting an $\mathrm{N}_{2}+\mathrm{H}_{2} \mathrm{O}$ mixture with hot charcoal. The temperature of charcoal will consequently affect the chemical composition and carbon potential of the atmosphere. According to a previous investigation, ${ }^{[6]}$ the higher the charcoal temperature, the higher the carbon potential of the atmosphere. However, the carbon potential would not remain at a steady level if the charcoal temperature was controlled at a specified value by using a temperature controller. This is because charcoal will be gradually consumed during the generation of water-gas atmosphere. Moreover, the gas velocity through the charcoal layer will also affect the chemical composition and carbon potential of the atmosphere. Investigating the feasibility of controlling the carbon potential of watergas atmosphere through controlling the charcoal temperature through use of an oxygen sensor and a computer is the purpose of this study. The water-gas atmosphere was generated by introducing an $\mathrm{N}_{2}+\mathrm{H}_{2} \mathrm{O}$ mixture into a charcoal furnace to react with hot charcoal. The $\mathrm{O}_{2}$ partial pressure of the atmosphere was monitored by using an oxygen sensor, the electromotive force (emf) output of which was fed back to a computer. The computer emitted a signal to control the heating current of the charcoal furnace and, consequently, to control the temperature of charcoal. Steel samples were meanwhile heated in the water-gas atmosphere. The feasibility of controlling the carbon potential of water-gas atmosphere by using the preceding method was assessed on the basis of the equilibrium carbon content of the heated steel and the stability of the oxygen sensor's emf output.

\section{EXPERIMENTAL METHOD}

The experimental apparatus is schematically shown in Figure 1. Bottled nitrogen was introduced into a flask, 


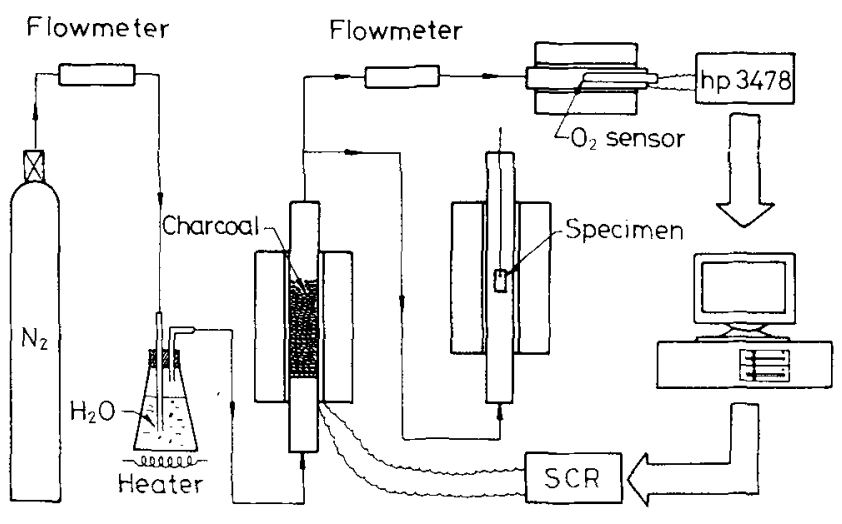

Fig. 1-Experimental apparatus.

filled with water, at a flow rate of $400 \mathrm{cc} / \mathrm{min}$. The temperature of water was controlled at $30{ }^{\circ} \mathrm{C}$ to $50{ }^{\circ} \mathrm{C}$. The nitrogen flowing out from the flask contained a given amount of water vapor which was dependent on the temperature of water. The higher the temperature of water, the greater the amount of water vapor in nitrogen. The exact amount of $\mathrm{H}_{2} \mathrm{O}$ contained in the $\mathrm{N}_{2}+\mathrm{H}_{2} \mathrm{O}$ mixture could be measured through measuring the dew point of the mixture using a dew cup. For example, the dew point of the $\mathrm{N}_{2}+\mathrm{H}_{2} \mathrm{O}$ mixture was approximately $30{ }^{\circ} \mathrm{C}$ (namely, $\mathrm{H}_{2} \mathrm{O}$ content was about $4.18 \mathrm{pct}$ ) when the water temperature was $35{ }^{\circ} \mathrm{C}$; the dew point of the $\mathrm{N}_{2}+\mathrm{H}_{2} \mathrm{O}$ mixture was approximately $40^{\circ} \mathrm{C}$ (namely, $\mathrm{H}_{2} \mathrm{O}$ content was roughly $7.3 \mathrm{pct}$ ) when the water temperature was $45{ }^{\circ} \mathrm{C}$. Such $\mathrm{N}_{2}+\mathrm{H}_{2} \mathrm{O}$ mixtures were passed through the hot charcoal layer in the charcoal furnace to generate water-gas atmospheres. The connecting pipe from the flask to the charcoal furnace was heated by a resistance wire to avoid the condensation of $\mathrm{H}_{2} \mathrm{O}$ from the $\mathrm{N}_{2}+\mathrm{H}_{2} \mathrm{O}$ mixture during transport. The watergas atmosphere generated in the charcoal furnace was separated into two flows: one was introduced at a flow rate of $100 \mathrm{cc} / \mathrm{min}$ into the oxygen testing furnace where $\mathrm{O}_{2}$ partial pressure of the atmosphere was monitored by an oxygen sensor; the other was introduced into the steel heating furnace where steel samples were heated under the water-gas atmosphere.

The solid electrolyte of the oxygen sensor was a $\mathrm{ZrO}_{2} \cdot \mathrm{CaO}$ tube with one end closed. Air was used as the reference gas of the sensor. The temperature of the oxygen testing furnace was controlled at $950{ }^{\circ} \mathrm{C}$ when an oxygen partial pressure was measured. The following relationship exists between the $\mathrm{O}_{2}$ partial pressure of water-gas atmosphere and the emf output of oxygen sensor. ${ }^{[11]}$

$$
E=0.0496 T\left(-0.678-\log P_{02}\right)
$$

where $E=$ the emf output of oxygen sensor (mv);

$T=$ the temperature of oxygen sensor $(\mathrm{K})$; and

$P_{02}=$ the oxygen partial pressure of water-gas atmospheres (atm).

According to Eq. [1], the lower the oxygen partial pressure, the greater the emf output of oxygen sensor. On the other hand, the oxygen partial pressure is closely related to the carbon potential of the atmosphere. The carbon potential of the atmosphere can therefore be controlled by controlling the emf output of oxygen sensor. A programmable voltmeter (HP 3478) was used for measuring the emf output of oxygen sensor. The emf received by the voltmeter was fed back to the computer which emitted signals to control the temperature of the charcoal furnace by using ON-OFF, proportional (P), proportional-integral (PI), or proportional-integraldifferential (PID) control mode with the aim of controlling the emf of atmosphere to remain at a given level. Experiments were conducted by using various control modes and control parameters, including delay time, control frequency, proportional coefficient, integral coefficient, differential coefficient, etc. The variances in charcoal temperature and oxygen sensor's emf output were recorded. Steel samples were, meanwhile, heated in the water-gas atmosphere. The effects of control modes and control parameters on the carbon potential control results of water-gas atmosphere were investigated on the basis of the equilibrium carbon content of the heated steel and the stability of the emf output of oxygen sensor.

The steel sample used in this study was a rather low carbon steel foil JIS-SPCE (cold-rolled carbon steel strip for extra deep drawing use, 0.057 pct C, 0.08 pct Si, 0.28 pct $\mathrm{Mn}, 0.023$ pct $\mathrm{P}$, and $0.022 \mathrm{pct} S$ ) with a thickness of $0.05 \mathrm{~mm}$. The dimensions of the specimen used were $10 \times 20 \times 0.05 \mathrm{~mm}$.

\section{RESULTS AND DISCUSSION}

\section{A. Relationship Between Charcoal Temperature and the Emf Output of Oxygen Sensor}

The following experiment was performed to establish the relationship between charcoal temperature and the emf output of oxygen sensor. The $\mathrm{N}_{2}+\mathrm{H}_{2} \mathrm{O}$ mixture containing 4.18 pct $\mathrm{H}_{2} \mathrm{O}$ was introduced into the charcoal furnace to generate water-gas atmosphere. The water-gas atmosphere was then introduced at a flow rate of $100 \mathrm{cc} / \mathrm{min}$ into the oxygen testing furnace where the $\mathrm{O}_{2}$ partial pressure of the atmosphere was measured with an oxygen sensor. During generation of water-gas atmosphere, the charcoal temperature was controlled at a given level or changed from one steady level to another level by using a temperature controller. The variance with time in the emf output of oxygen sensor was recorded. The results are shown in Figures 2 and 3 . The variance in emf is shown in Figure 2 when the charcoal temperature was raised to $910^{\circ} \mathrm{C}$ from $850^{\circ} \mathrm{C}$. The emf increased as the charcoal temperature was raised to $910{ }^{\circ} \mathrm{C}$. However, the time when the emf began to increase is 4 minutes later than when the charcoal temperature began to increase. The emf was still increasing and did not yet reach a steady value 2 hours after the charcoal temperature was raised to $910{ }^{\circ} \mathrm{C}$. The variance of emf is shown in Figure 3 when the charcoal temperature was lowered to $855^{\circ} \mathrm{C}$ from $900^{\circ} \mathrm{C}$. The emf output of oxygen sensor clearly decreased upon decreasing the charcoal temperature. However, the time at which the emf began to decrease was later than that for the charcoal temperature by 16 minutes. The emf roughly attained a steady level 1 hour after the charcoal temperature decreased to $855^{\circ} \mathrm{C}$. 


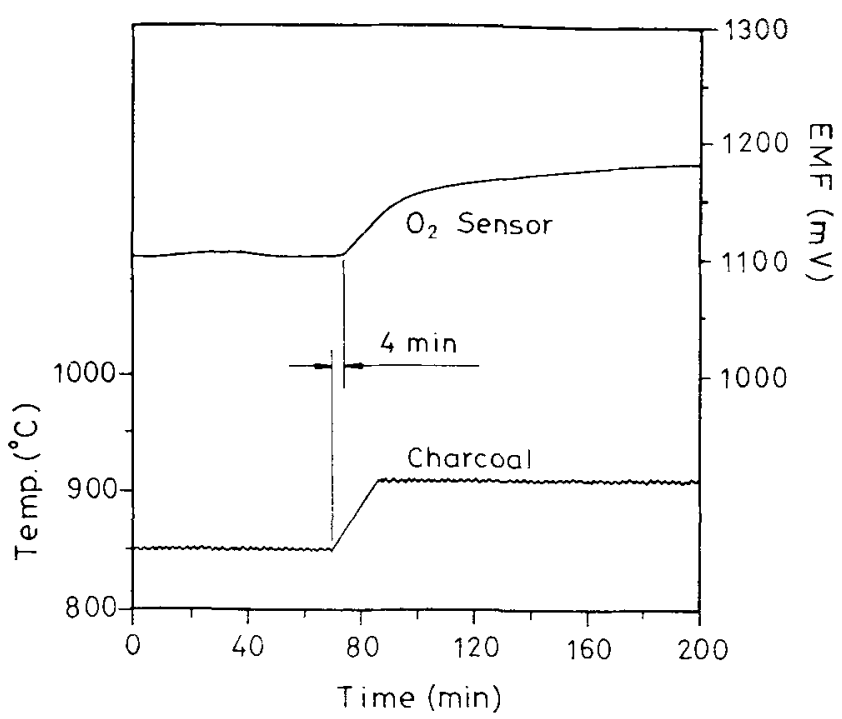

Fig. 2-Variation of the emf output of oxygen sensor when the temperature of charcoal was controlled at a constant level of $850^{\circ} \mathrm{C}$ and then raised to another level of $910{ }^{\circ} \mathrm{C}$

The following deductions can be established from the preceding experimental results. The emf output of oxygen sensor increases upon increasing the charcoal temperature; there is, however, a delay time of 4 minutes. The emf output of oxygen sensor decreases upon decreasing the charcoal temperature; there is, however, a delay time of 16 minutes. It takes a long time (over 2 hours) for the emf output to reach a steady level if the charcoal is controlled at a constant temperature. The emf output closely correlates with the carbon potential of the atmosphere. An unstable emf output implies an unstable carbon potential. Using a temperature controller to control the carbon potential of water-gas atmosphere through controlling charcoal temperature can therefore be inferred to not obtain a satisfactory result.

\section{B. The Control Result of Emf by Using ON-OFF Mode}

As mentioned previously, the emf output of oxygen sensor closely correlates with the carbon potential of the atmosphere. The stability of emf can represent the stability of carbon potential. The following experiment was done in order to understand the carbon potential control result for water-gas atmosphere by using ON-OFF mode. The emf output of oxygen sensor was intended to be controlled at a specified level through controlling the charcoal temperature by using various control parameters. Both the charcoal temperature and the emf output were recorded during the experiment. Figure 4 shows the variances with time in the practical temperature of charcoal and the practical emf of the atmosphere when the emf was intended to be controlled at $1150 \mathrm{mv}$ (denoted by the broken line) by using a control frequency of $1 \min ^{-1}$ (i.e., the heating current of charcoal furnace was controlled one time per minute by the ON or OFF signal emitted from the computer). Both the charcoal temperature and the emf can be seen from this figure to fluctuate over a wide range. The charcoal temperature

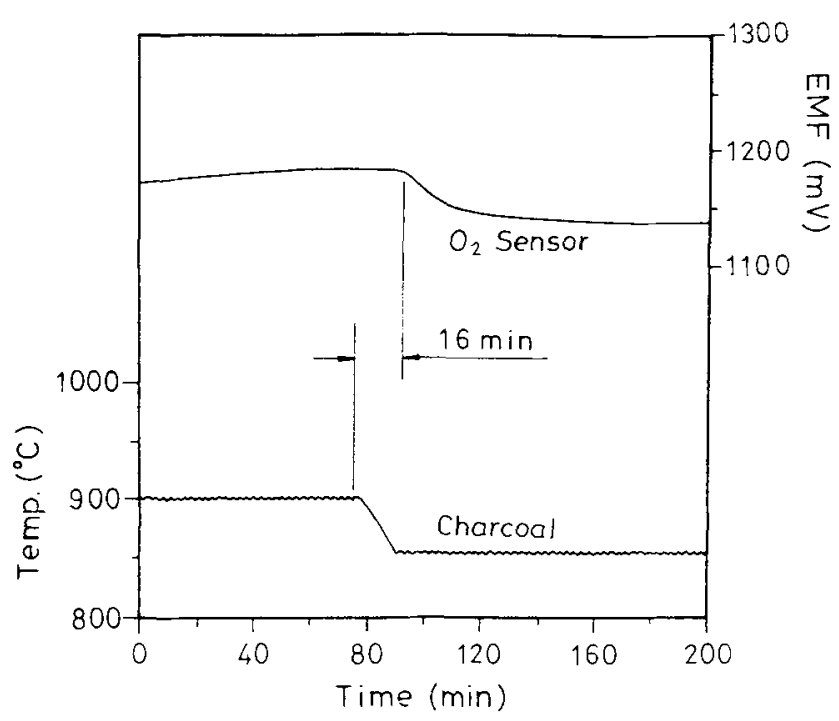

Fig. 3-Variation of the emf output of oxygen sensor when the temperature of charcoal was controlled at a constant level of $900{ }^{\circ} \mathrm{C}$ and then lowered to another level of $855^{\circ} \mathrm{C}$.

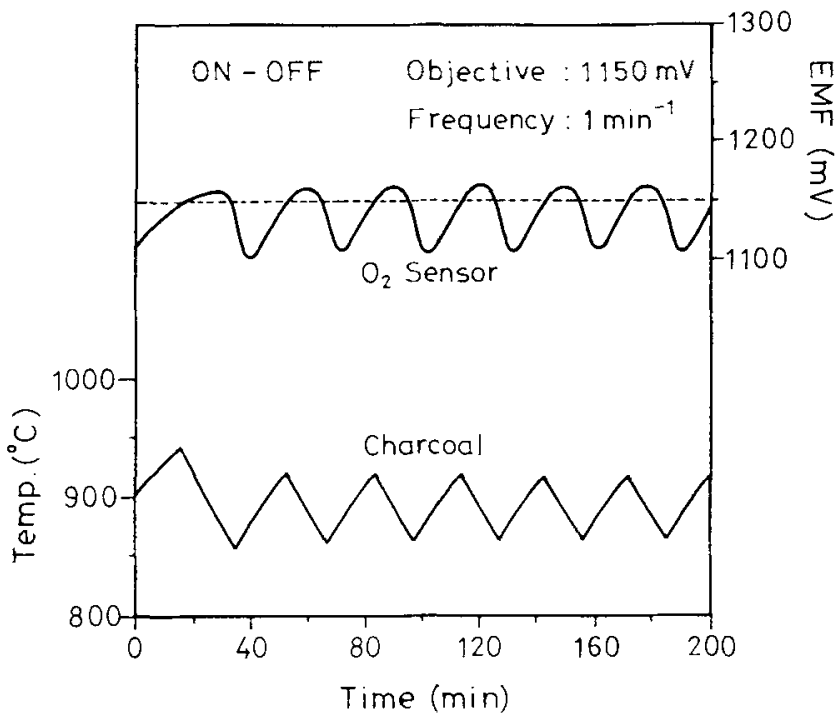

Fig. 4-Variations of charcoal temperature and the emf output of oxygen sensor which was intended to be controlled at $1150 \mathrm{mv}$ by using ON-OFF mode with a control frequency of $1 \mathrm{~min}^{-1}$.

fluctuates between $860^{\circ} \mathrm{C}$ and $920^{\circ} \mathrm{C}$; the emf fluctuates between 1110 and $1160 \mathrm{mv}$. The varying amplitude for emf is as wide as $50 \mathrm{mv}$. The mean value of practical emf (about $1135 \mathrm{mv}$ ) is, meanwhile, lower than the objective emf $(1150 \mathrm{mv})$ by $15 \mathrm{mv}$.

Two problems exist in the results of Figure 4. First, the fluctuating amplitude of emf is too large. Second, the mean value of emf is inconsistent with the objective emf. The reasons for this may be attributed to the low control frequency and not taking delay time into consideration. The delay time for changing emf can be seen from Figure 2 to be 4 minutes upon increasing the charcoal temperature. The delay time for changing emf can be seen from Figure 3 to be 16 minutes upon decreasing the charcoal temperature. The delay times during the periods of increasing and decreasing charcoal temperature 
(denoted by $a$ and $b$ respectively) were regarded as control parameters and taken into consideration during the experiment for the sake of obtaining a better result. The variances with time in practical emf and charcoal temperature have been shown in Figure 5 where the emf of the atmosphere was intended to be controlled at $1150 \mathrm{mv}$ by setting a parameter $a$ of 4 minutes, a parameter $b$ of 16 minutes, and a control frequency of $6 \mathrm{~min}^{-1}$. Both the charcoal temperature and the emf still fluctuate over some range; the fluctuating amplitudes, however, decrease significantly in comparison with those in Figure 4. For example, the fluctuating amplitude of emf decreases to $15 \mathrm{mv}$ in Figure 5 from $50 \mathrm{mv}$ in Figure 4. Besides, the mean value of emf is consistent with the objective emf; i.e., both are $1150 \mathrm{mv}$. A higher control frequency is seen from a comparison of the corresponding curves in Figures 4 and 5 to result in better control. In order to further establish the effect of control frequency on the control result, experiments were repeated under the same conditions as Figure 5 except that the control frequency was raised to $12 \mathrm{~min}^{-1}$. The results are shown in Figure 6. The fluctuating amplitude of emf clearly decreases to a value as small as $5 \mathrm{mv}$, and the mean value of emf is also consistent with the objective emf.

Two conclusions can be deduced from the results of Figures 4 through 6: (1) when the carbon potential of water-gas atmosphere is controlled by using ON-OFF mode, the fluctuating amplitude of emf can be reduced and the difference between the mean value of emf and the objective emf can be eliminated by taking the delay times of emf into consideration; (2) a higher control frequency leads to a smaller fluctuation of emf and, thus, a more stable result can be consequently obtained.

\section{The Control Result of Emf by Using P Mode}

The following experiment was performed to realize the result of controlling the emf of water-gas atmosphere

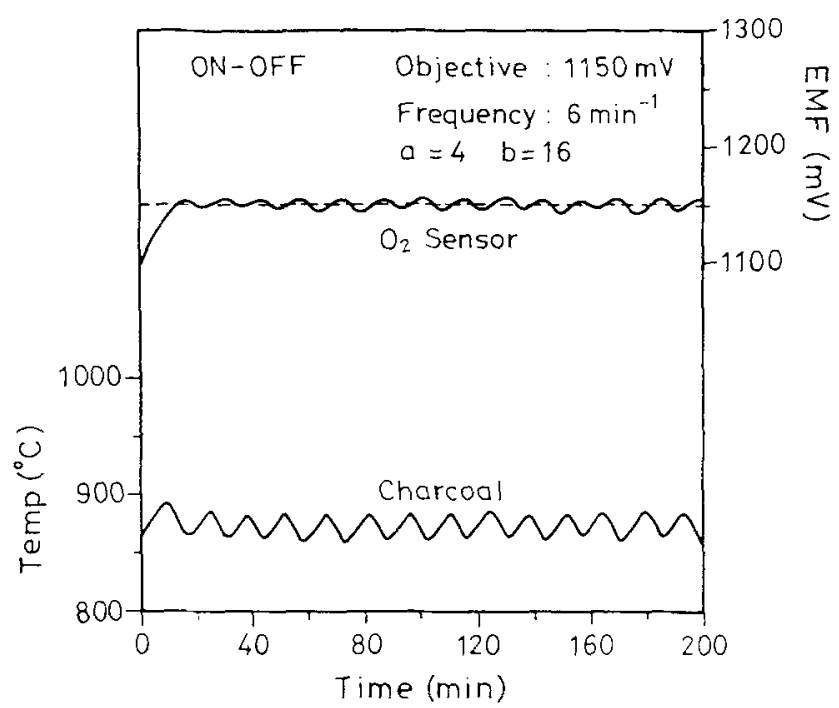

Fig. 5-Variations of charcoal temperature and the emf output of oxygen sensor which was intended to be controlled at $1150 \mathrm{mv}$ by using ON-OFF mode with a control frequency of $6 \mathrm{~min}^{-1}$ and control parameters $a=4$ and $b=16$. by using a $\mathrm{P}$ mode. The objective emf of atmosphere was set at $1150 \mathrm{mv}$. The respective lower limit and upper limit of proportional band were set at 1100 and $1200 \mathrm{mv}$. The emf of the atmosphere was automatically controlled by using $\mathbf{P}$ mode. The variances with time in charcoal temperature and the emf of atmosphere are shown in Figure 7. The fluctuating amplitude of both charcoal temperature and emf is seen in this figure to become smaller with time. The charcoal temperature and the emf, respectively, approach some steady level about 100 minutes from the beginning of control. Proportional control mode clearly has a substantial potential in reducing the fluctuating amplitude of emf in comparison with ON-OFF mode. A definite offset, however, exists

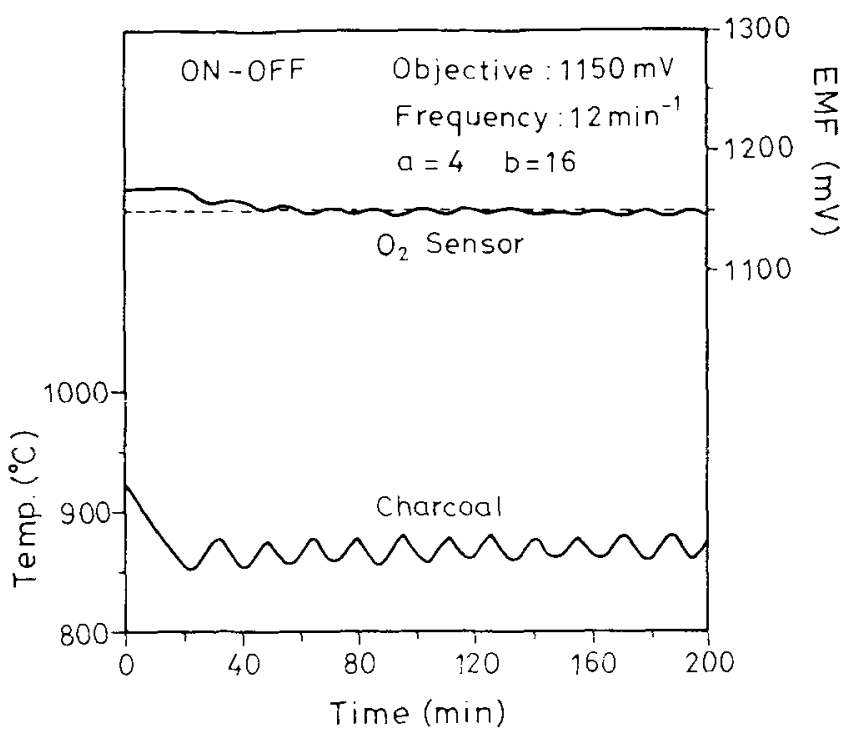

Fig. 6-Variations of charcoal temperature and the emf output of oxygen sensor which was intended to be controlled at $1150 \mathrm{mv}$ by using ON-OFF mode with a control frequency of $12 \mathrm{~min}^{-1}$ and control parameters $a=4$, and $b=16$.

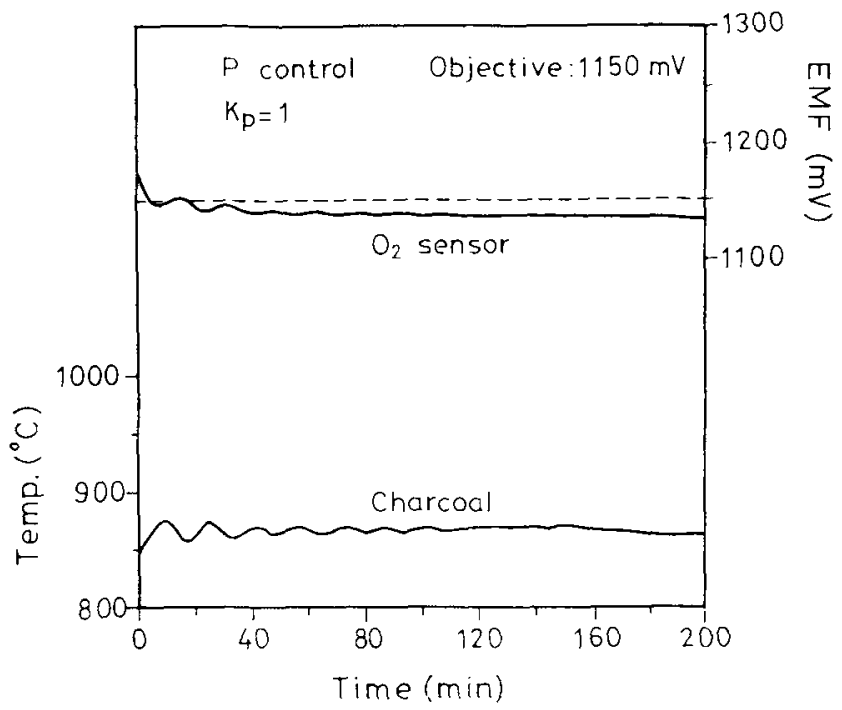

Fig. 7-Variations of charcoal temperature and the emf output of oxygen sensor which was intended to be controlled at $1150 \mathrm{mv}$ by using P mode with the control parameters $K_{\mathrm{p}}=1$. 
between the practical emf and the objective emf. This offset is approximately $15 \mathrm{mv}$ and will not die out with time. Restated, the emf of water-gas atmosphere can be easily controlled at a steady level by using P mode; this level is, however, not the objective emf.

\section{The Control Result of Emf by Using PI Mode}

In order to compensate the definite offset of $\mathrm{P}$ mode, an integral control mode (I mode) was taken into consideration in addition to $\mathrm{P}$ mode; i.e., the emf of watergas atmosphere was controlled by using PI mode. Both the coefficient of proportional item $K_{p}$ and the coefficient of integral item $K_{i}$ in control signals have to be assigned proper values, depending on the control system, for the sake of obtaining a satisfactory control result. Variances with time in charcoal temperature and the emf of atmosphere are shown in Figure 8 when the emf was intended to be controlled at $1150 \mathrm{mv}$ by using PI mode with $K_{p}$ of 1 and $K_{i}$ of 0.6. Both charcoal temperature and the emf of atmosphere are indicated by Figure 8 to be quite stable. No cycling appears on the recorded curves. Moreover, the emf of atmosphere can be controlled at the objective value in a short period of time (about 30 minutes) and does not significantly vary thereafter. Proportional-integral mode therefore has a good potential in eliminating the residual offset of $P$ mode and can control the emf of atmosphere to the objective value in a short time if both $K_{p}$ and $K_{i}$ have proper values.

\section{E. The Control Result of Emf by Using PID Mode}

Proper values were assigned to control parameters, including coefficient of proportional item $K_{p}$, coefficient of integral item $K_{i}$, and coefficient of differential item $K_{d}$. The emf of water-gas atmosphere was automatically controlled by using PID mode. The variances with time in charcoal temperature and emf were recorded. The results are shown in Figure 9 where the objective emf was

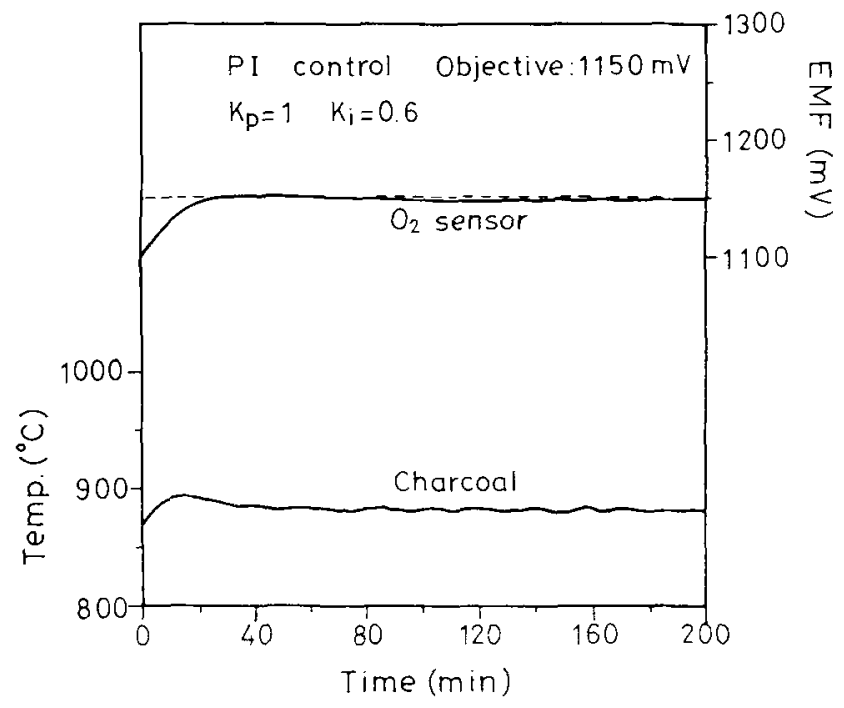

Fig. 8-Variations of charcoal temperature and the emf output of oxygen sensor which was intended to be controlled at $1150 \mathrm{mv}$ by using PI mode with the control parameters $K_{p}=1$ and $K_{i}=0.6$. set at $1150 \mathrm{mv}$ with control parameters $K_{p}$ of $1, K_{i}$ of 0.5 , and $K_{d}$ of 0.1 . Both the charcoal temperature and the emf of atmosphere can be seen from Figure 9 to be rather stable. The practical emf is completely consistent with the objective emf after reaching a steady state. Proportional-integral-differential mode with proper control parameters is implied by this phenomenon to be able to effectively control the carbon potential of water-gas atmosphere.

\section{F. The Control Result of Carbon Potential by Controlling Emf of the Atmosphere}

The emf of water-gas atmospheres was controlled to a given value by using various control modes, and steel samples were heated in such water-gas atmospheres. The stability of carbon potential was assessed through examining the equilibrium carbon content of the heated samples. This was done in order to understand whether the carbon potential of water-gas atmosphere could be effectively controlled or not by controlling the emf of the atmosphere. According to the experimental result, SPCE could achieve an equilibrium carbon content after being heated at $900{ }^{\circ} \mathrm{C}$ for 3 hours under the water-gas atmosphere generated by reacting an $\mathrm{N}_{2}+7.3$ pct $\mathrm{H}_{2} \mathrm{O}$ mixture with hot charcoal. Restated, the carbon content of SPCE heated for 3 hours under the water-gas atmosphere could represent the carbon potential of the atmosphere. The emf of water-gas atmosphere was intended to be controlled at $1150 \mathrm{mv}$ by using ON-OFF mode, and SPCE samples were heated, one after another, under the water-gas atmosphere at $900{ }^{\circ} \mathrm{C}$ for 3 hours. The carbon contents of the three heated samples are shown in Figure 10 to be 0.68 to 0.74 pct. The carbon potential of water-gas atmosphere is implied by this to be able to be nearly controlled at a constant level, with an error below $0.06 \mathrm{pct}$, if the emf of the atmosphere is controlled at a given level by using ON-OFF mode.

Figure 11 shows the carbon content of SPCE heated

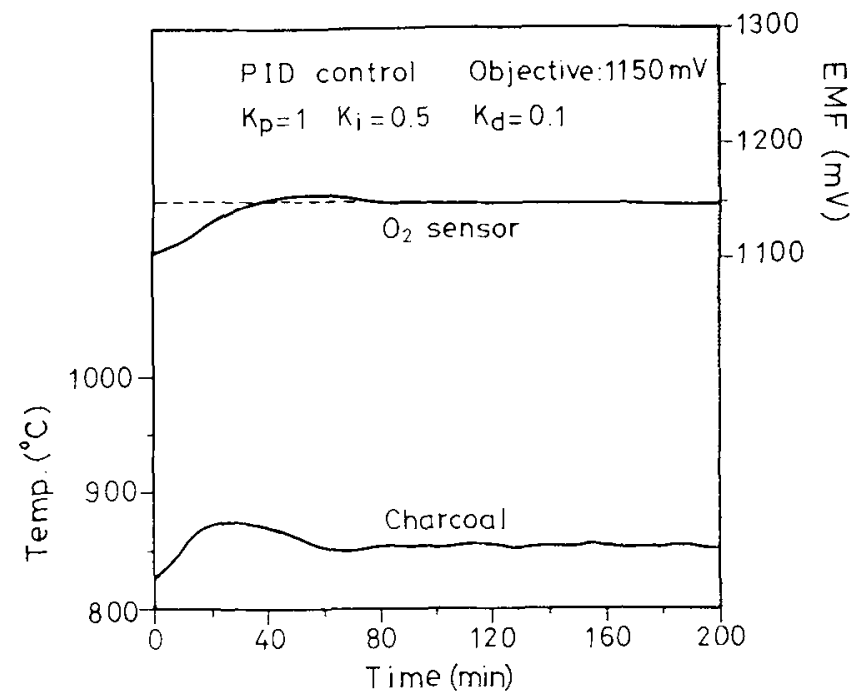

Fig. 9-Variations of charcoal temperature and the emf output of oxygen sensor which was intended to be controlled at $1150 \mathrm{mv}$ by using PID mode with control parameters $K_{p}=1, K_{i}=0.5$, and $K_{d}=0.1$. 


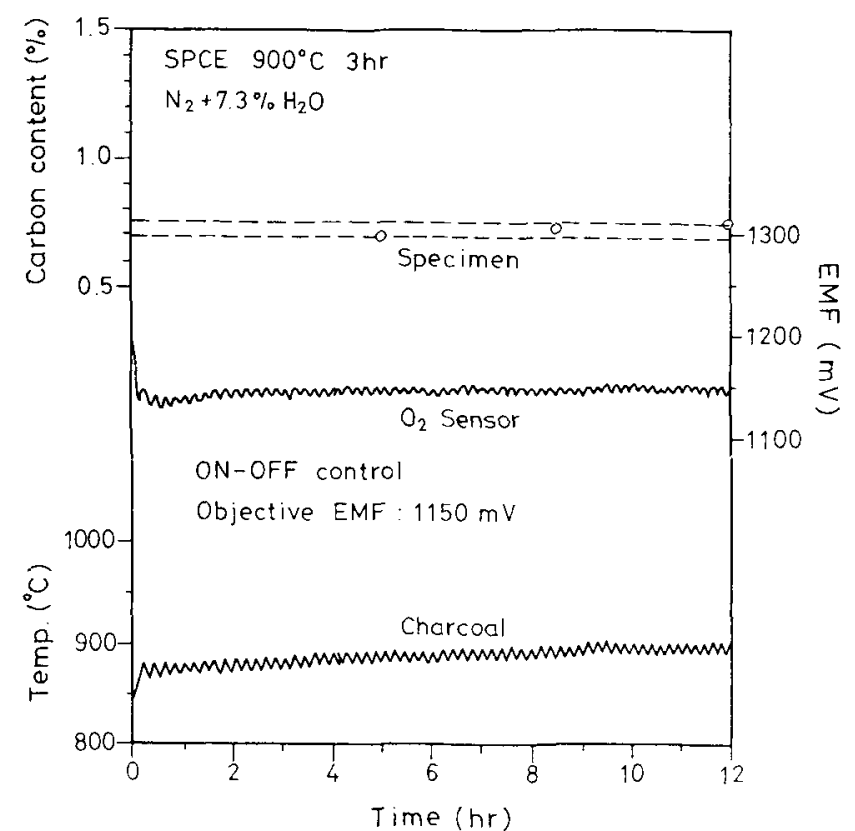

Fig. 10-Stability of carbon potential of the water-gas atmosphere, the emf of which was intended to be controlled at $1150 \mathrm{mv}$ by using ON-OFF mode

at $900{ }^{\circ} \mathrm{C}$ for 3 hours under the water-gas atmosphere, the emf of which was intended to be controlled at $1150 \mathrm{mv}$ by using PID mode. The carbon content for any of the three samples is clearly between 0.67 and $0.71 \mathrm{pct}$. This implies that if the emf of water-gas atmosphere is controlled at a given level by using PID mode, the carbon potential of the atmosphere will remain at a constant level, with an error less than 0.04 pct.

The carbon potential of water-gas atmosphere is seen from the results of Figures 10 and 11 to be able to be controlled at a steady level of approximately 0.7 pct when its emf is controlled at $1150 \mathrm{mv}$. To understand whether the carbon potential could converge to a steady level for other values of emf, experiments were repeated under the same conditions as Figure 11 except that the objective emf was raised to $1200 \mathrm{mv}$. The results are shown in Figure 12. The carbon content for any of the three samples heated under the atmosphere is between 1.03 and 1.09 pct. This again shows that the carbon potential of water-gas atmosphere remains constant as long as its emf is controlled at a constant level. The following conclusions can be drawn from comparison of Figure 12 with Figures 10 and 11. The higher the level at which the emf of water-gas atmosphere is controlled, the higher the carbon potential of the atmosphere. The carbon potential of water-gas atmosphere remains constant as long as its emf is kept constant. A small fluctuation of emf has no significant influence on the carbon potential of the atmosphere. The deviation of carbon potential of water-gas atmosphere can be controlled to be smaller than 0.06 pct through controlling the charcoal temperature via use of an oxygen sensor and a computer.

\section{G. Comparison with General Methods of Controlling Carbon Potential}

A general method used for controlling the carbon potential of atmosphere was stated in Section I to be to add

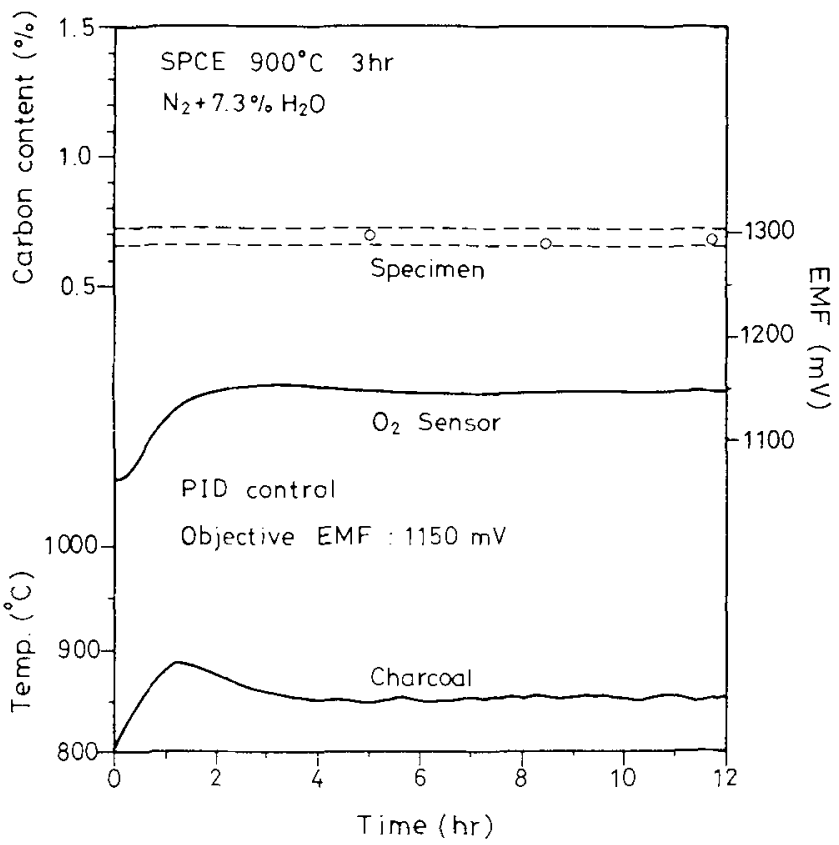

Fig. 11-Stability of carbon potential of the water-gas atmosphere, the emf of which was intended to be controlled at $1150 \mathrm{mv}$ by using PID mode.

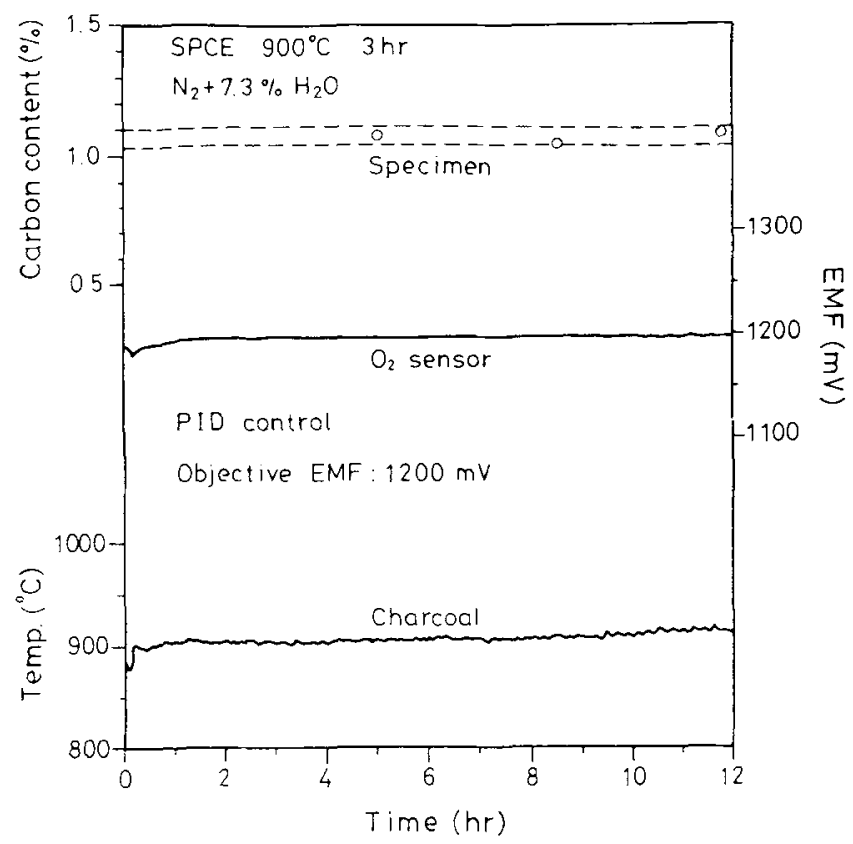

Fig. 12-Stability of carbon potential of the water-gas atmosphere, the emf of which was intended to be controlled at $1200 \mathrm{mv}$ by using PID mode.

enriched gas to the atmosphere; the carbon potential is controlled through controlling the amount of enriched gas being added. The method of controlling carbon potential used in this study, however, controls the generational condition of the atmosphere, namely, the charcoal temperature, instead of adding enriched gas to the atmosphere. The principles of these two methods are compared as follows. 
The components of a furnace atmosphere are generally $\mathrm{N}_{2}, \mathrm{CO}, \mathrm{H}_{2}, \mathrm{CO}_{2}, \mathrm{H}_{2} \mathrm{O}, \mathrm{CH}_{4}$, and small amounts of $\mathrm{O}_{2}$. The following equilibrium relationship exists when the equilibrium state between furnace atmosphere and steel is achieved.

$$
\mathrm{CO}_{2}+[\mathrm{C}] \Leftrightarrow 2 \mathrm{CO}
$$

where $[\mathrm{C}]$ represents the carbon dissolved in steel. The carbon content of steel and the partial pressures of $\mathrm{CO}$ and $\mathrm{CO}_{2}$ have the following relationship:

$$
K_{2}=\frac{P_{\mathrm{CO}}^{2}}{\alpha P_{\mathrm{CO} 2}}
$$

where $K_{2}$ is the equilibrium constant of Reaction [2] and $P_{\mathrm{CO}}$ and $P_{\mathrm{CO} 2}$, respectively, denote the partial pressure of $\mathrm{CO}$ and $\mathrm{CO}_{2}$. The term $\alpha$ represents the saturation degree for the carbon in austenite. In other words, $\alpha=$ $\mathrm{C}_{E} / \mathrm{C}_{S}$, where $\mathrm{C}_{S}$ stands for the saturated carbon content of austenite and $C_{E}$ is the equilibrium carbon content of steel heated in the atmosphere (namely, the carbon potential of the atmosphere). Both $K_{2}$ and $\mathrm{C}_{S}$ are kept constant if the heating temperature of steel remains unchanged. Therefore, the carbon potential of atmosphere will increase with increasing $\mathrm{CO}$ content or decreasing $\mathrm{CO}_{2}$ content. When enriched gas $\mathrm{CH}_{4}$ is added to the atmosphere, the $\mathrm{CH}_{4}$ will react with the $\mathrm{CO}_{2}$ in the atmosphere to form $\mathrm{CO}$ and $\mathrm{H}_{2}$ according to the following reaction:

$$
\mathrm{CH}_{4}+\mathrm{CO}_{2} \rightarrow 2 \mathrm{H}_{2}+2 \mathrm{CO}
$$

Hence, an addition of $\mathrm{CH}_{4}$ will lead to a decrease in $\mathrm{CO}_{2}$ and an increase in $\mathrm{CO}$, resulting in an increase in carbon potential of the atmosphere. Restated, the carbon potential of the atmosphere can be controlled by controlling the additional level of enriched gas.

As mentioned previously, water-gas atmosphere was generated by reacting an $\mathrm{N}_{2}+\mathrm{H}_{2} \mathrm{O}$ mixture with hot charcoal. The reactions are

$$
\begin{gathered}
\mathrm{C}+\mathrm{H}_{2} \mathrm{O} \rightarrow \mathrm{CO}+\mathrm{H}_{2} \\
\mathrm{C}+2 \mathrm{H}_{2} \mathrm{O} \rightarrow \mathrm{CO}_{2}+2 \mathrm{H}_{2}
\end{gathered}
$$

where $\mathrm{C}$ denotes the carbon in charcoal. Reaction [5] is primary for a relatively high charcoal temperature. Reaction [6] is primary for a relatively low charcoal temperature. As a result, the higher the charcoal temperature, the higher the $\mathrm{CO}$ content and the lower the $\mathrm{CO}_{2}$ content of the water-gas atmosphere. Restated, the carbon potential of water-gas atmosphere can be controlled by controlling the charcoal temperature.

On the other hand, the constituent gases $\mathrm{CO}, \mathrm{CO}_{2}$, and $\mathrm{O}_{2}$ of an atmosphere have the following equilibrium relationship:

$$
\begin{gathered}
\mathrm{CO}+\frac{1}{2} \mathrm{O}_{2} \Leftrightarrow \mathrm{CO}_{2} \\
K_{7}=\frac{\mathrm{P}_{\mathrm{CO}} \mathrm{P}_{\mathrm{O} 2}^{1 / 2}}{\mathrm{P}_{\mathrm{CO} 2}}
\end{gathered}
$$

where $K_{7}$ is the equilibrium constant of Reaction [7]. Decreasing the content of $\mathrm{CO}_{2}$ is seen from Reaction [7] to facilitate the reaction occurring to the right and, consequently, to reduce the partial pressure of $\mathrm{O}_{2}$. From the relationship $\alpha=C_{E} / C_{S}$ and Eqs. [8] and [3], the following relationship can be obtained:

$$
\mathrm{C}_{E}=\frac{K_{7} \mathrm{C}_{\mathrm{S}}}{K_{2}} \frac{\mathrm{P}_{\mathrm{CO}}}{\mathrm{P}_{\mathrm{O} 2}^{1 / 2}}
$$

$K_{2}, K_{7}$, and $\mathrm{C}_{S}$ are all constant if the heating temperature of steel is specified. The carbon potential of an atmosphere can therefore be seen from Eq. [9] to increase with an increase in the partial pressure of $\mathrm{CO}$ and/or a decrease in the partial pressure of $\mathrm{O}_{2}$. As for the atmospheres generally used in industry, e.g., endothermic gas, the partial pressure of $\mathrm{CO}$ is essentially determined by the kind of hydrocarbon gases from which the atmosphere is produced. The partial pressure of $\mathrm{CO}$ varies little as long as the kind of hydrocarbon gases is specified. The carbon potential of atmosphere can therefore be controlled through controlling the partial pressure of $\mathrm{O}_{2}$ by adding proper amounts of enriched gas. As for water-gas atmosphere, the partial pressure of $\mathrm{CO}$ is primarily determined by the $\mathrm{H}_{2} \mathrm{O}$ content in the $\mathrm{N}_{2}+\mathrm{H}_{2} \mathrm{O}$ mixture from which the water-gas atmosphere is generated. The partial pressure of $\mathrm{CO}$ changes little as long as the $\mathrm{H}_{2} \mathrm{O}$ content in the $\mathrm{N}_{2}+\mathrm{H}_{2} \mathrm{O}$ mixture remains unchanged. ${ }^{[12]}$ The carbon potential of water-gas atmosphere can therefore be controlled by controlling the oxygen partial pressure through controlling charcoal temperature, and there is no need to add enriched gas to the atmosphere. This is the special feature of this study.

\section{CONCLUSIONS}

When water-gas atmosphere was produced by reacting an $\mathrm{N}_{2}+\mathrm{H}_{2} \mathrm{O}$ mixture with hot charcoal, the carbon potential of the atmosphere increased upon increasing the charcoal temperature. The carbon potential could not, however, reach a steady level in a short time if the charcoal temperature was controlled at a constant level using a temperature controller. The carbon potential as well as the emf of water-gas atmosphere could be effectively controlled, with an error below 0.06 pct, through controlling the charcoal temperature via use of the control unit comprised of an oxygen sensor and a computer if the control mode and control parameters were properly selected. The control result of carbon potential would be improved if the delay time of emf were taken into consideration. Besides, a more stable result could be obtained if a higher control frequency were adopted. The advantage of this method was that the tedious process of adding enriched gas could be waived.

\section{ACKNOWLEDGMENT}

The author wishes to acknowledge the National Science Council of Taiwan, Republic of China, for the financial support of this research under Grant No. NSC 80-0405-E002-14. 


\section{REFERENCES}

1. ASM Metals Handbook, 10th ed., 1991, vol. 4, pp. 508-81.

2. K.D. Gladden, M.F. Simmons, and R.H. Hays: Met. Prog., 1978, vol. 113 (4), p. 40.

3. T.M. Meyers: Met. Prog., 1978, vol. 113 (4), p. 36.

4. C.A. Stickels, C.M. Mack, and J.A. Pieprzak: Metall. Trans. $B$, 1980, vol. 11 B, p. 485.

5. Y.C. Chen and C.H. Hwang: J. Heat Treat., 1985, vol. 4 (1), p. 75

6. Y.C. Chen and C.H. Hwang: Heat Treat. Met., 1984, vol. $11(4)$, p. 96
7. Y.C. Chen and G.S. Lu: Heat Treat. Met., 1991, vol. 18 (4), p. 110.

8. Y.C. Chen, K.C. Chi, and C.H. Hwang: Chin. J. Mater. Sci., 1987 , vol. 19 (4), p. 262.

9. Y.C. Chen, B.S. Yu, and C.H. Hwang: Chin. J. Mater, Sci, 1989, vol. 21 (3), p. 169.

10. Y.C. Chen: Chin. J. Mater. Sci., 1992, vol. 24 (1), p. 1.

11. C.H. Hwang, P.S. Lu, and R.C. Sohn: Chin. J. Mater. Sci., 1974, vol. 11 (4), p. 29.

12. Y.C. Chen and R.B. Jaw: Bull. Coll. Eng., National Taiwan University, Taiwan, 1991, vol. 52, p. 13 